\title{
INSTRUCCIONES PARA COLABORADORES
}

1. CLARIDADES. REVISTA DE FILOSOFÍA se concibe como revista de filosofía que publicará prioritariamente los trabajos relacionados con el simposio anual que la propia revista organiza.

2. Las colaboraciones para CLARIDADES. REVISTA DE FILOSOFÍA se harán llegar a la revista remitiéndolas al correo-e:

\section{Revista@filosofiaenmalaga.net.}

3. Proceso de aceptación:

a) El Consejo editorial de la revista, consultado -en su caso- el Consejo asesor puede aceptar, sugerir modificaciones o rechazar los textos recibidos, y así se lo comunicará a los autores.

b) Reservará una parte de su contenido a los estudiantes de filosofía de la Universidad de Málaga. La intención es que los estudiantes del departamento de filosofía de la Universidad de Málaga puedan ir adquiriendo las habilidades específicas para su posterior dedicación científica. Como medida preferente el consejo editor indicará los errores que deben subsanar para que los artículos cumplan los requisitos necesarios para su publicación. De este modo la revista pretende cumplir en la medida de sus posibilidades con el papel de formación de los estudiantes.

c) En ningún caso se publicarán trabajos anónimos.

4. No se establece un tamaño específico para los trabajos

5. En cuanto a las citas, se solicita a los autores sencillamente que cumplan su función; es decir, que permitan al lector localizar el texto de referencia: a) para lo cual el autor tiene la libertad de usar mayúsculas o minúsculas, cursivas, negritas, subrayados y demás recursos tipográficos de la manera que le convenga; b) CLARIDADES. REVISTA DE FILOSOFÍA se reserva, a su vez, la libertad de -sin alterar el contenido- modificar el formato recibido para dar homogeneidad al número. 
6. Referencias bibliográficas: deberán presentarse en un listado final con el siguiente formato:

-ARTÍCULOS DE REVISTA: Vigo, A.:"Prioridad ontológica y prioridad lógica en la doctrina aristotélica de la sustancia" en Philosophica 13, 1990, pp. 17-51

-LIBRO: Zubiri, X.: Cinco lecciones de filosofía. Madrid: Ed. Alianza, 1980 p. 18.

- Los textos clásicos se citarán conforme al formato habitual, y en su caso no será necesario indicar el número de páginas: Platón: Fedro, 227d.

- CAPÍTULO DE LIBRO: Price, D.: "A general theory of bibliometric and other cumulative adventage processe" en Griffith, B.C.: Key paper information science. New York: Knowledge Industry Publications, 1980, pp. 177-191.

- DOCUMENTO ELECTRÓNICO: Morin, E. [en línea]: “La epistemología de la complejidad", en Gazeta de Antropología 20 (2004) (trad. José L. Solana), http://www.ugr.es/ pwlac/G20_02Edgar_Morin.html [Consultado: $26 / 12 / 2006$ 